\title{
Are World Heritage concepts of integrity and authenticity lacking in dynamism? A critical approach to Mediterranean autotopic landscapes.
}

Juan A. García-Esparza juan.garcia@uji.es

Landscape Research

\begin{abstract}
This paper examines how contemporary on-going and lively debate on Critical Heritage Studies merges with previous discourses on World Heritage Cultural Landscapes and rural societies. The scholarly approach to authenticity and integrity, and the critical point of static and dynamic approaches to these terms allow the author to challenge previous World Heritage (WH) discourses with a view to obtaining innovative insight into abandoned vernacular landscapes. Two main arguments are thus developed in this study. The first of these is an overview of the dynamics of abandoned cultural landscapes on an international scale. The second is an inside view aiming to provide an accurate interpretation of how these landscapes should be scrutinised and understood. To do this, autotopias and heterotopias broach the fundamental issue of how the Outstanding Universal Value of attributes in abandoned cultural landscapes needs to be understood, enhanced, experienced, and managed in an innovative WH approach. In conclusion, complex proposals for these heritage landscapes should rely on understanding the dynamics of the material and the social construct of the habitats they contain in order to assess them effectively from the standpoint of a World Heritage Cultural process Assemblage rather than that of Outstanding Material Stratification.
\end{abstract}

\section{KEYWORDS:}

Abandoned vernacular landscapes; static authenticity; dynamic authenticity; integrity; utopic heritage;

\section{Introduction}

There are some issues concerning how 'landscape experience' is approached. This paper highlights the difficulty of translating traditional conservation concepts to dynamic landscape contexts, focusing on authenticity and integrity, as well as concerns over the resulting management. Broadening the concept of heritage to terms linked to territory and the legislative translation found in World Heritage Cultural Landscapes (WHCL) opens up new possibilities for recognising heritage values in abandoned cultural landscapes. This involves a potential reassessment of the imperatives of both institutional statements and factual deregulation, relating to what Harrison (2017) has referred to as the heritage of absence. Critical heritage studies examine the right of different peoples to value emptiness, decay and loss, and even the sadness and attachment sometimes caused by these perceptions (García-Esparza, 2017). 
Part of this is due to the conflict between the preservationist ethos of the World Heritage Site (WHS) designation and attempts by locals to achieve economic and social development. In this respect, problems relating to the WHS designation may revolve around potentially counterproductive fixed ideas of conservation values in dynamic and heterogeneous rural landscapes. Today, it is widely accepted that the vernacular not only involves rural streetscapes, field and landscape patterns or traditional uses, but also involves memories and senses moulded by the contemporary structure -economy and culture- of the place. In this regard, the vibrant discourse on heritage resiliency, heterodox approaches to heritage studies (Lixinski 2015), critical heritage studies (Winter 2013) and heritage in transition or heritage by appropriation (Tweed and Sutherland 2007) can all be applied to abandoned cultural landscapes.

This article will present an inside view, aiming to provide an accurate and provocative interpretation of how the vernacular is scrutinised and understood, referencing the scholarly framework that UNESCO has set up as regards authenticity and integrity. Secondly, the peculiarities of abandoned cultural landscapes are showcased as an ethnic palimpsest in which landscape history and re-enactment may play a double role. Thirdly, the cultural and visual acceptance of the abandoned landscape will be stressed contrasting "static" and "dynamic" in discourse and ideas on heterotopias and autotopias.

Starting with the definition of two categories of cultural landscape: (ii) "a continuing landscape, closely associated with a traditional way of life, which is continuing to evolve and exhibits significant material evidence of its historic evolution" and (iii) "an associative cultural landscape whose material cultural evidence may be insignificant or even absent" (Fowler, 2003), this critical analysis focuses on the concepts of "continuing to evolve", "significant material evidence" or "historic evolution" as regards material cultural evidence.

Focusing on definition (ii) and further analysing the concept of cultural landscape, UNESCO (2003, pp.5559) stresses the need to understand that complex handmade objects in inherited landscapes need to be reused and adapted to present living and working conditions. However, UNESCO also references problems linked to concepts such as "alteration, continuity, overlapping, contrast/harmony and decontextualization"; a critical process which may reveal that over time the interpretation of historical and architectural aspects might change depending on who is assessing them.

This authorised discourse has been found in several past conventions where cultural landscape has been analysed from an object-focused approach. The ways in which these object-focused landscapes have been "perceived" by "the artistic contemplation", "the scenery or setting values" or their "harmony" (UNESCO, 2003, pp.60-67) have ignored the autotopian values of landscape.

There are other major semantic problems with autotopian approaches to landscape. For instance, the term "indigenous people" has been used to highlight "the importance of the spiritual wealth of humanity, and its complex relationships with the natural environment" (UNESCO, 2004, pp.45-48). However, this seemingly remote and unexploited concept of indigenous people could also be applied to contemporary rural societies worldwide given that these operate and resolve heritage issues differently from the authorised pattern. The maintenance of local diversity and active social roles must therefore be regarded as the continuous adaptation of these pseudo-indigenous people. Firstly, rural (abandoned or not) cultural landscapes should probably be approached as habitats rather than "settings" (Martin \& Patti, 2009) "which exhibit significant material evidence of its historic" -and contemporary- "evolution". Ways of life are evolving, as is material evidence. This concept becomes all the more important as language appropriation may wrongly refer solely 
to landscapes as illustrating "the evolution of human society (...) reflecting past land-use and activities" (UNESCO, 2003, pp.60-67) without taking into consideration that today these uses and activities are still being transformed or adapted. The question thus arises: from whom and for whom are these transformations being perceived, evaluated and integrated into knowledge? Accordingly, it remains unclear whether the contemporary evolution of this material evidence is properly assessed within the scholarly framework to avoid the homogenisation of physical manifestations of contemporary rural communities, by using an authorised understanding of heritage to negate their creativity and expression.

\section{The scholarly framework. Authenticity and integrity}

It has been said that cultural landscapes should illustrate the evolution of human society and settlement over time, under the influence of internal and external physical constraints. Various international declarations (Council of Europe, 1975; UNESCO, 1976; ICOMOS, 1987) have echoed the significance of public opinion and support and the need for conservation work to be socially progressive, stressing the special attention required by the Mediterranean landscape (Council of Europe, 2006: 72). Seeking to conserve an ever-changing environment, the need for sites to evolve and experience socio-cultural change (Assi, 2000) was recognised by ICOMOS (1994). Strategic work within UNESCO is on-going and incorporates elements such as ruralscapes, cultural routes, rural morphologies, functionality, genius loci and intangible values (Rodwell and van-Oers, 2007).

In short, rural landscape management is partly about conserving individual structures and artefacts, but also involves "judgements about the spirit of place as a living entity from the past, in the present, and for the future" (Pendlebury et al, 2009). There is therefore a need to embrace change (Hoggart et al. 1995), even when it remains unclear how the concepts of integrity and authenticity fit in with these dynamics. It has been suggested that the definitions of integrity and authenticity require further elaboration so as "not to exclude cultural continuity through change, which may introduce new ways of relating to and caring for the place" (UNESCO, 2001: 18-19).

Bearing in mind the six main criteria for assessing the Outstanding Universal Values (OUVs) of attributes in cultural landscapes, it is worth noting criterion 5, the criterion against which most rural landscapes submitted for WHCL declarations are measured (Gullino and Larcher, 2013).

To be a remarkable example of a traditional human settlement, land use, or sea use which is representative of a culture (or cultures), or human interaction with the environment especially when it has become vulnerable under the impact of irreversible change.

Studies on the integrity of rural landscapes show that the interaction between man and natural environment was considered to be the unique universal value. Each of these landscapes was recognised as cultural heritage because of its distinctive agricultural system, traditional crops, local products and historical land uses, bearing in mind that the most important markers of integrity, as seen by UNESCO, are reflected in historical features and architectures relating to the agricultural activity of the site. Integrity remains an elusive concept for which UNESCO provides no clear definition.

ICOMOS resorted to the definition provided by Jokilehto (2007) for the terms structural and visual integrity. Structural integrity was referred to as "what has survived from its evolution over time". This 
wording suggests that the process of evolution has continued up until the present, and now "the survival" is under control (Martin \& Patti, 2009).

In the Working Papers mentioned earlier, integrity was firstly acknowledged for its visual importance, but concepts relating to zoning or excessive control were queried as processes inevitably replacing existing social, cultural and economic diversity. The stance of ICOMOS highlighted the need to consider the importance of the characteristics of a property's social, economic and cultural time and place as much as its physical (visual) context. In addition, the need "to prescribe new approaches to definition and use of integrity and authenticity" was once again considered. Similarly, the position held by ICCROM stressed that the Operational Guidelines would require additional careful examination to ensure that terms such as integrity and authenticity were consistent and helpful.

As regards integrity, UNESCO (2015) highlights the wholeness and intactness of cultural heritage and its attributes. The seemingly rather static view does not allow for too much diversity and continuity because "adverse effects of neglect" should not exist or even be referred to. The Operational Guidelines state that for properties nominated under criteria (i) to (vi) the physical fabric should be in good condition and the impact of the (dynamic) deterioration process controlled (statically). This apparently static conception of the term integrity seems to contradict the need for cultural landscapes to maintain "dynamic functions" in order to allow diversity and contemporary evolution; concerns regarding "alteration, continuity, overlapping, contrast/harmony and decontextualization" have not yet been solved.

The analysis of different approaches to the study of authenticity in heritage reveals that most studies focus on two main poles. Authenticity, as defined by Wang (1999), refers to whether heritage objects are historically accurate or not. From individual perspectives on heritage, authenticity has been seen as an existential experience derived from consumption (Gilmore \& Pine, 2007; Moscardo, 2001; Wang, 1999), despite being viewed as the scenic visualisation of the vernacular (García-Esparza 2015) or as what Urry (1990) has referred to as the leisure consumption of heritage.

Other authors have linked the concept of authenticity to the logic of parasites (Puleo, 2013) and the problems in highlighting sites with multiple past functions and present meanings. This difficult task has been criticised for potentially making it necessary "to analyse (cull) the desirable, paralyse (eliminate) the objectionable, and catalyse (combine) the preferred" (Fig. 1).

UNESCO (2015) holds that authenticity must be considered and judged primarily within the cultural contexts to which it belongs, expressing its significant attributes. The Nara document on authenticity bases values and authenticity on the ability to understand historical periods and the original characteristics of cultural heritage and its meanings. In spite of the Nara +20 convention stressing the need for authenticity to accommodate changes in perceptions and attitudes over time, nothing was said about making, as authentic heritage-making referred not only to locals' understanding and actions but also to the structural context derived from the current social, cultural and economic continuity of landscapes and their rural societies.

It has recently been said that integrity should entail a "comprehensive reading" while authenticity must make it possible "to appreciate the veracity of the character" (Mata, 2016). Therefore, comprehensiveness and veracity regarding the contemporary evolution of materiality may suggest extrapolating dynamism to objects or even to the perception of integrity and authenticity, a point that will be discussed further. 
Veracity and character appear to be the two terms that lead towards an authentic original but dynamic response to place. Stovel (2007) talked about "the ability of the good to convey meanings over time", but which interpretations could provide meanings in the analysis of abandoned cultural landscapes? This is not yet clear, and new paradigms are needed to perceive and assess cultural landscapes, first accepting these as evolving habitats where narratives and facts merge in several ways so that authenticity - sometimes permanent, sometimes merging, and occasionally transcending our understanding - can be understood in its "solid, liquid and gas state". As this cannot be controlled, an approach to the concept should probably be more physiological than material.

\section{Insight into Abandoned Cultural Landscapes}

The history of human land use in the Mediterranean Basin Area reflects successive waves of human population growth and decline, with the first traces of human activity dating back to Neolithic settlements (Gasco and Gutherz, 1983). Since the Middle Ages most of the Mediterranean highlands have undergone changes. The original scattered medieval settlements in the highlands and their successive layers of occupation came about from necessity, which led to self-sufficiency in exploiting land resources. This gave rise to a less natural landscape which displayed many features of highly humanised space. The recent history of these landscapes continues to evoke the necessity and faith of recent history in vernacular Mediterranean landscape.

Vernacular dwellings, epitomising a medieval culture based on mobility and living off the land, came to be seen as a symbol of stability, independence, attachment to the land, and of a code of conduct and morality (Jackson, 1990). Despite major economic and social changes, the autonomous households, the surviving spatial patterns, the buildings' arts and crafts, and the territorial histories contributing to this context persist until the present day.

These landscapes bear considerable witness to human adaptation in regions with scarce living resources: extreme orographic conditions, terraced slopes, extensive grazing land, fields for reaping, vineyards and fruit crops. Horticulture and agro-pastoral activities came to fully exploit the existing resources. These landscapes bear witness to and demonstrate exceptional responses to the continuous evolution of human settlements. These continuously populated lands have also been directly affected by periods of war and dictatorships, marking the start of a process of abandonment and depopulation, later worsened by owners moving from the hinterland to the coast towards the better paid activities resulting from economic development in the final decades of the $20^{\text {th }}$ century.

Several landscapes fitting this description of Mediterranean physiognomy have already been listed under Criterion 5 as world heritage properties under threat from modern economic development, rural depopulation and the abandonment of traditional agricultural practices. These include The Holy Valley and the forest of Cedars of God (Lebanon) or Portovenere, Cinque Terre (Italy), listed in 1998 and 1992 respectively for "the harmonious interaction between people and nature to produce a landscape of exceptional scenic quality that illustrates a traditional way of life". In the twenty-five years since this declaration it has become clear that these were included for their visual integrity and material-original authenticity. Despite the absence of specific information, it can be assumed that the abandonment, transformation, and decay of the traditional way of life in the hinterlands were ignored. 
The integrity of another two recent inclusions (2011), the Cultural Landscape of Sierra de Tramuntana (Spain) and Causses and Cévennes, Mediterranean agro-pastoral Cultural Landscape (France) has been analysed differently. Although the project for the former was accepted for its visual integrity, which it had "retained to a considerable extent", the fragility of the structural integrity was also pointed out as being "due to the progressive increase of tourism". In the case of Causses and Cévennes, the project made no mention of visual or structural integrity. This wholeness and intactness were associated with the intangibility of agro-pastoralism, said to be almost obsolete in the landscape of the time.

In terms of authenticity, the case of the Tramuntana highlights the decline in traditional dynamic processes. However, this landscape has been preserved thanks to the awareness of the many wealthy artists and intellectuals living in this evocative setting. In the case of Causses and Cévennes, this relict landscape was said to have maintained a certain degree of authenticity in need of conservation. Nevertheless, in both cases, once the social construction of the landscape is disrupted, rural landscapes replace their simplicity with other rather different new material processes.

Due to the control referenced above, no mention was made of the values of contemporary adaptations of materiality. UNESCO deals with these candidacies treating landscape as something outstanding, evolving over centuries but rescued from contemporary pervasive threats, instead of understanding certain forms of contemporary eclecticism, abandonment, decay or even destruction deriving from uncontrolled actions. Of course, not all forms of eclecticism, abandonment or reconstruction may be valid, but when referring to the rural landscapes of necessity and faith, any form of social reconstruction will probably lead to honest and respectful conservation of its material form.

In a later declaration (2014), the Vineyard Landscape of Piedmont: Langhe-Roero and Monferrato, UNESCO declared that the property possessed the qualities of cultural, residential, architectural, environmental and productive integrity. With these defining qualities, integrity is seemingly acquiring the range of definition searched for throughout the last decade. Nevertheless, the criteria for ascertaining the validity of cultural and architectural continuity are not specified.

None of the WHCL mentioned earlier refer to the authenticity and integrity of the sincere response to rural life, inherited vernacular architecture, or the contemporary architecture of "humble" pseudo-indigenous people - excessively patronised by our understanding or neglect. This intellectual appropriation is therefore leading to an architecture devoid of the spontaneous expression of humility, necessity and faith. Thus, folklore and other types of intangible performance can clearly be pure yet spontaneous and contemporary. Why is this not true of architectural objects to the same extent? (Fig. 2\&3). This architecture is only produced when the contemporary socio-economic and cultural integrity of the landscape and its structure co-exist with abandonment, decay or "latent" maintenance, enabling "dynamic integrity and authenticity" to be found together with the continuity of the materiality of the property in itself.

\section{Cultural and visual acceptance. From whom and for whom?}

The terms visualisation and authenticity in landscapes, as referred to by UNESCO, do not just denote how a landscape is evolving and is affected in material terms. They also relate to how the past is viewed and experienced by locals and foreigners -a key aspect in many heritage studies (Waitt, 2000)- and to whether it offers a sense of identity and anchors collective memory by providing tangible links between past, present 
and future (Millar, 1989). In this sense, while views and perceptions of landscape are not merely deeply rooted in society, the way a landscape evolves is a characteristic factor with a culturally dependent outcome. Cultural landscapes such as those of necessity and faith are defined as "geographic areas associated with a historic event, activity, or people exhibiting cultural and aesthetic values" (Birnbaum \& Peters, 1996). According to this definition, these landscapes are experiential cultural spaces involving a complex set of elements. These cultural or even sacred landscapes are imbued with meanings and beliefs. They are places where the intangible -non-fixed- can acquire greater significance than fixed or semi-fixed elements (Lennon and Taylor, 2012; Rapoport, 1984). Thus, within the non-fixed elements the heritage of absence can acquire tremendous relevance in the feelings of those re-enacting the landscape.

In light of previous research, two major trends appear in Europe in terms of the perceptions of abandoned landscapes. The first reflects rejection, while the second highlights the poetic connotations and feelings of freedom associated with such spaces (Hunziker, 1995; Rouay-Hendrickx, 1991). The social impact brought about by the enclosure of landscape by forests and the loss of scenic qualities, together with depopulation and the loss of perception of a well-managed landscape, can give rise to feelings of desolation, isolation, oppression, and loss of contact (Bell et al., 2009; Benjamin, Bouchard, \& Domon, 2007). In keeping with this, some believe that the landscape is defaced by the enclosure of mountain landscapes, the disappearance of contours, and the loss of spatial hierarchies (Liou, 1991; Pérez, 1990).

These visual effects can give rise to negative feelings of apathy and disaffection in some people while others experience the poignancy and beauty often lacking in the maintained anthropic elements. A recent study addressing stakeholders' perceptions of these abandoned landscapes states that the majority viewed them negatively. While those with apathetic and anthropocentric values may be mainly influenced by the poor condition of the anthropic elements, those with ecocentric values may experience positive perceptions, not necessarily perceiving these spaces in terms of possible profit but instead appreciating them for reasons potentially associated with landscape quality (Arriaza et al., 2004; Nassauer, 1995; Nijnik \& Mather, 2008; Rogge et al., 2007) (Fig. 4).

The high values associated with managed landscape are also featured in several studies evaluating the quality of certain environments (Kaur et al., 2004; Rogge et al., 2007; Zheng et al., 2011). Nassauer (2011) suggests that visible evidence of care and attention towards the landscape evokes an aesthetic response which makes the viewer feel good. However, land management no longer has the sole purpose of producing economic benefits, but serves the multifunctional needs of society, including non-market benefits such as recreation and Quality of Life Capital, as well as an ecosystem service approach to assure biodiversity. As Domon (2011) notes, while before it was the ability to produce goods which was the basis for landscape appreciation, now it is aesthetic, environmental and heritage qualities which are decisive factors in the appreciation of rural spaces.

Landscapes have an important tale to tell, highly influenced by the successive layers of socio-economic and cultural evolution of each place. The perception, valuation, and re-enactment of abandoned cultural landscapes rely on knowledge. Given that landscape is something to be constructed, not just physically but intellectually, the recognition of more than one epistemology should not be ruled out. Knowing and helping others to know how a present layer is a response to previous layers and the framework for later changes will directly affect the way a landscape is managed. 
One of the many ways to understand the history of landscape change is recognising that change itself is actually a part of landscape (Fairclough, 2012), even if change means abandonment. What now? Do we always seek to preserve the fabric, or could readability of subtler traces be enough? The answer may depend on whether the observer is looking for the cultural process of landscape, which is dynamic, or for the visual experience, which takes place in a spatially static landscape.

\section{What now? Dynamic authenticity and integrity?}

In its Operational Guidelines, UNESCO states that cultural properties are exposed to several dangers. Negative impacts are defined as "social, economic and other pressures or changes" (dynamism) "that might affect the effective protection of the (static) "property" (UNESCO, 2015), pervasive threats through which any sort of interaction may have an uncontrollable outcome.

This seemingly static visualisation, control and protection can be discussed in terms of heterotopia and autotopia. Foucault (1986) defined heterotopias as "real places", places that exist and were formed at the very foundation of society. To some extent these are like countersites, a type of successfully enacted utopia in which real sites are simultaneously represented, challenged, and inverted. However, heterotopias break the normal continuity of time and space, recently seen as an operational dysfunction. For this reason UNESCO is calling for an appraisal of potential dangers "according to the normal evolution of the social and economic framework".

Autotopia, in contrast, refers to spatial practices where the role of the non-expert is empathised, where ordinary residents participate in the intellectual and material construction of places (Fairclough, 2012). This is slightly different from the role of architectural historian, referred to in the Operational Guidelines as the spirit of the Charter of Venice, and transcends the conceptualisation of contemporary vernacular and ethnic landscape (García-Esparza, 2015). Autotopias understand abandonment and decay as well as the technical ingenuity born from necessity, the autotopian place is slightly dangerous, yet exciting and democratic (Fig. $5)$.

Nowadays autotopias are considered by UNESCO to be threats, as their dynamic character is opposed to the static mechanisms of "control and effective protection". Any uncontrolled variability is considered to have a potential impact, but how then should we deal with the reality of social and cultural pluralism, and the resulting plural meanings? Riley (1990) already pointed out that landscapes need taxonomy, comprehensive frameworks demanding collective intention in this age of specialists, for better or for worse. Abandoned cultural landscapes can be referred to as anthropological interactions between housing, settlements, and landscapes (Augé 1998). Rapoport (1972) believed that human nature combines elements of constancy and change in relation to biological nature, perception and behaviour, which are culturally linked and therefore changeable, innate and constant. This being said, abandoned cultural landscapes should contain complementary perspectives where the autotopian construction has the same or even greater importance than the heterotopian one.

More recently, Bortoloto (2015) referred to authenticity as an extrinsic process while Kristensen (2015) emphasised the need to focus on the social value of authenticity. Jones (2010) related dynamism to the concept of authentic self, the way in which a historical object or landscape responds authentically to the moment. Given that the term "value" was recognised by the Nara Document to determine authenticity 
(ICOMOS 1994) in relation to original and subsequent characteristics of cultural heritage, several authors have linked this term to the social construct of a given time and place. This means that value involves understanding the nature of the valued object, "static authenticity", without disregarding the nature of the value expressed for an object, "dynamic authenticity".

Dynamic authenticity is about present perception, action, experience, and social practice (May and Thrift 2001), about values of time and place (Gibson and Pendlebury 2009), about objects not just being part of the space but also making or transforming it today (Crang 2001) (Fig. 6). The dynamically authentic object is directly affected by contemporary decision-making processes and is the result of cumulative sociocultural reconstructions by humble cultures. Thus, its value resides in how the object reflects the circumstances rather than in the importance of the element itself.

Irrespective of the cultural background, flows or transmigrations, static authenticity is found in every heritage object which somehow retains or values embedded values from the past today. It is fundamentally based on the materiality of the object. Thus, static authenticity needs to be forcefully implemented by dynamic authenticity if the heritage object is to provide a sincere response to context, time, and place. Accordingly, dynamic and static authenticity interact only to the extent to which each culture understands, allows, and regulates these interactions in every landscape, object, form, practice, and relationship.

Static authenticity has been at the core of conservation criteria ever since it became synonymous with historic original materiality. Pendlebury (2013) highlighted the importance of the value-based norms associated with conservation-planning practice while emphasising the dynamism of actions and relationships. Dynamic authenticity was probably first considered when ICOMOS (1999) introduced two terms into the conservation processes: meanings and interpretation. While this clearly referred to public participation in the decision-making process, the critical analysis in this paper aims to extend this reference to terms of autotopian participation and autotopian understanding of landscapes.

\section{A future for abandoned cultural landscapes}

UNESCO (2004, pp.36-42) highlighted the importance of intangible values as powerful elements of history, tradition, spiritual inspiration and politics. At the time, the visual integrity-focused approach to landscape was influenced by tourist considerations. This line of thought has now been disproved as the tangible and intangible object-approach gave rise to social inequity.

Members of UNESCO (2004) emphasised the need to acknowledge the value of place in integrating continuity towards the future, although no conclusions were drawn on how to set up the mechanisms to ensure appreciation and continuous construction in communities. In fact, it is not yet clear how integrity and authenticity can be adapted to achieve this. Instead, despite the fact that "the evolution of the local value should not be impaired", it is clearly impaired by a strict control which only permits the authorised. It should not just be about consulting and involving inhabitants in the process, but should allow them to build up their own habitat, as any other control mechanism would negate spontaneous humble expression born from the structural context of necessity and faith.

In order to understand that these landscapes have strong material components not to be denied in any way but adapted or maintained, any approach to habitat would require giving priority to the knowledge of pseudo-indigenous peoples', allowing them to value abandonment, decay and reconstruction as an intrinsic 
part of the process. It is unlikely that the outcome will match the authorised visual integrity, but will instead be the result of managing evolution without diminishing character, supporting a fluid and permeable social construct of the habitat, while avoiding strict control mechanisms.

The task of preserving the OUV of attributes in abandoned cultural landscapes consists in permanently rethinking options for integrity and authenticity. Nowadays, UNESCO suggests an integrated approach to guiding the evolution of properties to ensure their maintenance. At this point, a distinction should be made between the terms material maintenance and maintenance of the social construct. The latter covers both the wider public and the (private) owners of the properties, and includes not only perceptions and associations but feelings and sense of belonging.

It is not easy to manage the process of maintaining families in abandoned cultural landscapes, re-enacting the lives of previous generations who inhabited landscapes out of necessity and faith. When dealing with this type of long-term action, which looks to maintain and re-inhabit the OUV there are certain "risks and threats" which cannot be "controlled". When such values are not easily detected or even understood by the wider public, there is a need for the transmission and recognition of knowledge. Once this cycle is complete, effective awareness is achieved, but not necessarily the protection expected.

As mentioned earlier, public re-enactment is not just about visual perception but is a psychological understanding of what is culturally inherited and the process by which any autotopian action may change the future of these landscapes. Thus, maintenance and public participation, as interpreted through previous conventions and guidelines, appear as obsolete static concepts since "the need to respond to the dynamic changes of the contemporary world" has not been defined nor does it "respect different approaches in the context of specific cultures" (Martin \& Patti, 2009, p. 21). This research, an answer to a question posed in that meeting, emphasises the need to understand and adapt integrity and authenticity in order to properly maintain and preserve endemic landscapes from specific geo-cultural regions.

Mediterranean abandoned cultural landscapes would need the implementation of a soft management plan and perhaps a different kind of WHS designation. Why is it not possible to temporarily link designations to the foreseen dynamism of a given landscape? This question eventually leads to a designation through which control, impact, protection, and safeguards can be understood in a more fluid fashion. In this temporal designation autotopia is an intrinsic part of the process. This idea builds on the cultural process of a WHCL designation rather than on the awarding of the designation itself.

\section{Conclusion}

Abandoned cultural landscapes result in spontaneous afforestation and the dilution or loss of certain cultural landscape features. Reconstructing the cultural process of a partially abandoned WHCL is thought to ensure integrated continuity. Critical analysis of the term continuity shows that the approach to this concept should be twofold, examining both material and social continuity. According to UNESCO, continuity should be judged within the cultural context, although no mention has been made of contemporary cultural appropriation, creativity and expression. Another notable omission is that of mechanisms to ensure communities are able to benefit from the appreciation and continuous construction of the landscape, finding ways to rethink integrity and authenticity options in order to do so.

This paper has thus attempted to provide a different perspective to enrich the dialogue. In a bid to ensure a more social- than object-focused approach to WHCL, it is suggested that abandoned cultural landscapes 
should be approached as endemic habitats where endangered species -rural societies- in a process of continuous adaptation still inhabit the landscape. This would require the implementation of static authenticity and integrity in the dynamics so that attributes provide accurate responses in terms of time and place. UNESCO does not explain how these interactions could take place, as some of these dynamics are perceived as threats. This paper therefore emphasises the need for these dynamic and static qualities in attributes to interact only to the extent to which each culture understands, allows, and regulates them so that landscapes retain their sincerity and credibility.

Dynamic integrity and authenticity in landscapes have been sustained by the term autotopia. This has been defined as the spatial practices where the role of the non-expert is in empathy with ordinary residents participating in the intellectual and material construction of places. Autotopias understand abandonment and decay as well as the technical ingenuity born from necessity. The habitat approach to abandoned cultural landscapes gives priority to the recomposition of the cultural process allowing inhabitants to value abandonment, decay and reconstruction as an intrinsic part of the cultural process. Thus, the maintenance mentioned above should be understood as the maintenance of both the dynamic material and the social construct. If this dialectic process is achieved, the material and social continuity of a cultural landscape can be effectively built on the idea of a World Heritage Cultural Process Assemblage rather than on that of an Outstanding Material Stratification. 


\section{Acknowledgements}

This research has been developed with funding from the project "World Heritage Cultural Landscapes List. Keys for their identification and criteria for their management" from the Ministry of Economy and Competitiveness in Spain, MINECO. CSO2015.65787-C6-6-P.

Some of the ideas included in this paper were presented by the author at the ICOMOS University Forum Workshop on Authenticity and Reconstruction (Paris, 13-15 March 2017). The group in which these ideas where discussed was chaired by Mr. Cornelius Holtorf, with the participation of Alkindi Al Jawabra, Erica C. Avrami, Marcia Bezerra, Anaëlle Cambon, Tamas Fejérdy, Juan A. García-Esparza, Rodney Harrison, Nour Munawar, Junko Okahashi, Mariana Patiño and Nino Sulfaro. Finally, I would also like to thank the reviewers for their invaluable comments.

\section{References}

Assi, E. (2000). Searching for the concept of authenticity: implementation guidelines. Journal of Architectural Conservation, 6 (3): 60-69.

Augé, M. (1998). Hacia una antropología de los mundos contemporáneos. Barcelona: Gedisa.

Arriaza, M., Cañas-Ortega, J. F., Cañas-Madueño, J. A., Ruiz-Aviles, P. (2004). Assessing the visual quality of rural landscapes. Landscape and Urban Planning, 69 (1): 115-125.

Bell, S., Montarzino, A., Aspinall, P., Peneze, Z., Nikodemus, O. (2009). Rural society, social inclusion and landscape change in Central and Eastern Europe: A case study of Latvia. European Society for Rural Sociology. Sociologia Ruralis, 49 (3): 295-326.

Benjamin, K., Bouchard, A., Domon, G. (2007). Abandoned farmlands as components of rural landscapes: An analysis of perceptions and representations. Landscape and Urban Planning, 83(4): 228-244.

Birnbaum, C.A., Peters, C.C. (Eds.) (1996). The Secretary of the Interior's Standards for the Treatment of Historic Properties with Guidelines for the Treatment of Cultural Landscapes. Washington: US Department of the Interior.

Bortolotto, C. (2015). UNESCO, cultural heritage, and outstanding universal value: value-based analyses of the World Heritage and Intangible Cultural Heritage Conventions. International Journal of Heritage Studies, 21 (5): 528-530.

Crang, M. (2001). "Rhythms of the city: temporalised space and motion.” In TimeSpace: Geographies of Temporality, edited by Jon May and Nigel Thrift, 187-207. London, New York: Routledge.

Council of Europe. (1975). European Charter of the Architectural Heritage. Strasbourg, Council of Europe Publishing.

Council of Europe. (2006). Landscape and sustainable development. Challenges of the European Landscape Convention, 72. Strasbourg, Council of Europe Publishing.

Domon, G. (2011). Landscape as resource: Consequences, challenges and opportunities for rural development. Landscape and Urban Planning, 100(4): 338-340.

Fairclough, G. (2012). "A prospect of time. Interactions between landscape architecture and archaeology." In Exploring the boundaries of landscape architecture, edited by Simon Bell, Ingrid Sarlöv Herlin, Richard Stiles, 83-114. London, New York: Routledge.

Foucault, M. (1986). Of Other Spaces. Diacritics, 16 (1): 22-27. 
Fowler, P.J. (Ed.) (2003). World Heritage Cultural Landscapes 1992-2002. World Heritage Papers 6. Paris: UNESCO World Heritage Centre.

García-Esparza, J.A. (2017). Discussion on: Creating heritage-making futures? In: Holtorf, C., Kealy, L., Kono, T. A contemporary provocation: reconstructions as tools of future-making. ICOMOS University Forum on Authenticity and Reconstructions. (Personal Communication, Paris, 13 March 2017).

García-Esparza, J. A. (2015). Epistemological paradigms in the perception and assessment of vernacular architecture. International Journal of Heritage Studies, 21 (9): 869-888.

Gasco, J., Gutherz, X. (1983). Premiers paysans de la France méditerranéenne. First Farmers of the French Mediterranean, Montpellier, France: Direction du Patrimoine du Ministère de la Culture.

Gibson, L., Pendlebury, J. (2009). "Valuing historic environments.” In Valuing historic environments, edited by Lisanne Gibson and John Pendlebury, 1-18, Farnham: Ashgate.

Gilmore, J. H., \& Pine, B. J. Jr. (2007). Authenticity: What consumers really want? Boston. MA: Harvard Business School Press.

Gullino, P., Larcher, F. (2013). Integrity in UNESCO World Heritage Sites. A comparative study for rural landscapes. Journal of Cultural Heritage, 14: 389 - 395.

Harrison, R. (2017). Discussion on: Creating heritage-making futures? In: Holtorf, C., Kealy, L., Kono, T. A contemporary provocation: reconstructions as tools of future-making. ICOMOS University Forum on Authenticity and Reconstructions. (Personal Communication, Paris, 13 March 2017).

Hoggart, K., Buller, H., and Black, R. (1995). Rural Europe. Identity and Change. London: Hodder and Stoughton.

Hunziker, M. (1995). The spontaneous reafforestation in abandoned agricultural lands: Perception and aesthetic assessment by locals and tourists. Landscape and Urban Planning, 31(1-3): 399-410.

ICOMOS (1987). Charter on the Conservation of Historic Towns and Urban Areas: 'The Washington Charter'. Paris: ICOMOS.

ICOMOS (1994). The Nara Document on Authenticity. Paris: ICOMOS.

ICOMOS. (1999). 1979. Charter for Places of Cultural Significance: 'The Burra Charter'. Australia: ICOMOS.

Jackson, J.B. (1990). “The Future of the Vernacular Landscape.” In Vision, culture and landscape, edited by Paul Groth, 27-39, Berkeley: University of California.

Jones, S. (2010). Negotiating Authentic Objects and Authentic Selves: Beyond the Deconstruction of Authenticity. Journal of Material Culture, 15: 181-203.

Jokilehto, J. (2007). International charters on urban conservation: some thoughts on the principles expressed in current international doctrine. City \& time, 3 (3): 23-42.

Kaur, E., Palang, H., \& Soovali, H. (2004). Landscapes in change - Opposing attitudes in Saaremaa, Estonia. Landscape and Urban Planning, 67(1-4): 109-120.

Kristensen, T. M. (2015). Pilgrimage, devotional practices and the consumption of sacred places in ancient Egypt and contemporary Syria. International Journal of Heritage Studies 21 (4): 354-368.

Lennon, J. L., Taylor, K. (2012). "Prospects and Challenges for Cultural Landscape Management." In Managing Cultural Landscapes, edited by Ken Taylor and Jane L. Lennon, 345-364. New York: Routledge. Liou, V. (1991). Méthode d'approche des friches dans le parc naturel régional du pilat. Revue de géographie de Lyon, 66: 55-60. 
Lixinski, L. (2015). Between orthodoxy and heterodoxy: the troubled relationships between heritage studies and heritage law. International Journal of Heritage Studies, 21 (3): 203-214.

Martin, O. and Patti, G. (Eds.) (2009). World Heritage and Buffer Zones. World Heritage Papers 25. Paris: UNESCO World Heritage Centre.

Mata, R. (2016). Discussion on: Paisajes patrimoniales, In: García-Esparza, J.A. Simposio internacional sobre paisajes culturales de la lista de patrimonio mundial. Universitat Jaume I. (Personal Communication, Castellón de la Plana, 28 September 2016).

Millar, S. (1989). Heritage management for heritage tourism. Tourism Management, 10(1): 9-14.

Moscardo, G. (2001). Cultural and heritage tourism: The great debates. In B. Faulkner, G. Moscardo, \& E. Laws (Eds.), Tourism in the 21st Century (pp. 3-17). London: Continuum.

Nassauer, J. I. (1995). Culture and changing landscape structure. Landscape Ecology, 1(4): 229-237.

Nassauer, J. I. (2011). Care and stewardship: From home to planet. Landscape and Urban Planning, 100(4): 321-323.

Nijnik, M., \& Mather, A. (2008). Analyzing public preferences concerning woodland development in rural landscapes in Scotland. Landscape and Urban Planning, 86(3/4): 267-275.

Pendlebury, J., Short, M., \& While, A. (2009). Urban World Heritage Sites and the problem of authenticity. Cities, 26: 349 - 358.

Pendlebury, J. (2013). Conservation values, the authorised heritage discourse and the conservationplanning assemblage. International Journal of Heritage Studies, 19 (7): 709-727.

Pérez, M.R. (1990). Development of Mediterranean agriculture: an ecological approach. Landscape and Urban Planning. 18: 211-220.

Puleo, T. J. (2013). Parasitizing landscape for UNESCO World Heritage. Geoforum, 45: 337 - 345.

Rapoport, A. (1972). Vivienda y cultura. Barcelona: Gustavo Gili.

Rapoport, A. (1984). The meaning of the built environment: A non-verbal communication approach. London: Chapman and Hall.

Riley, R. (1990). "Bigger Than a Breadbox, Smaller Than the Cosmos: Twenty Questions About the Landscape Experience.” In Vision, culture and landscape, edited by Paul Groth, 1-10, Berkeley: University of California.

Rodwell, D, van-Oers, R. (2007). Management and Preservation of Historic Centers of Cities inscribed on the World Heritage List (summary report). Paris: World Heritage Centre.

Rogge, E., Nevens, F., \& Gulinck, H. (2007). Perception of rural landscapes in Flanders: Looking beyond aesthetics. Landscape and Urban Planning, 82(4): 159-174.

Rouay-Hendrickx, P. (1991). La perception de la friche: étude méthodologique. Revue de géographie de Lyon 66: 27-37.

Stovel H. (2007). Effective use of authenticity and integrity as world heritage qualifying conditions. City \& Time, 2 (3): 3.

Tweed, C., Sutherland, M. (2007). Built cultural heritage and sustainable urban development. Landscape and Urban Planning, 83 (1): 62-69.

UNESCO (1976). Recommendation Concerning the Safeguarding and Contemporary Role of Historic Areas. Nairobi: UNESCO. 
UNESCO (2001). Report of the Thematic Expert Meeting on Asia-Pacific Sacred Mountains. Paris: UNESCO World Heritage Centre: 18-19.

UNESCO (2003). Cultural Landscapes: the Challenges of Conservation. World Heritage Papers 7. Paris: UNESCO World Heritage Centre: 60-67.

UNESCO (2004). Linking Universal Values: Managing a Sustainable Future for World Heritage. World Heritage Papers 13. Paris: UNESCO World Heritage Centre.

UNESCO (2015). Operational Guidelines for the Implementation of the World Heritage Convention. http://whc.unesco.org/en/guidelines [Accessed: June 26, 2015].

Urry, J. (1990). The Tourist Gaze: Leisure and Travel in Contemporary Societies. London: Sage.

Waitt, G. (2000). Consuming heritage: Perceived historical authenticity. Annals of Tourism Research, 27: $835-862$.

Wang, N. (1999). Rethinking authenticity in tourism experience. Annals of Tourism Research, 26: 349370.

Winter, T. (2013). Clarifying the critical in critical heritage studies. International Journal of Heritage Studies, 19 (6): 532-545. 